Moustafa S. Darweesh et al., Studying of water hammer in water supply pipes network with different abnormal operation conditions (case study-Assiut city network), pp. 2036 - 2054

\title{
STUDYING OF WATER HAMMER IN WATER SUPPLY PIPES NETWORK WITH DIFFERENT ABNORMAL OPERATION CONDITIONS (CASE STUDY - ASSIUT CITY NETWORK)
}

\author{
Nashat A. Ali, Gamal Abozeid and Moustafa S. Darweesh * \\ Staff in Civil Engineering Department, Faculty of Engineering, Assiut University
}

Received 25 September 2013; accepted 25 October 2013

\begin{abstract}
This research studies the effect of abnormal operation conditions on water hammer phenomenon in water supply pipe network in order to provide an acceptable level of protection against system failure due to pipes collapse or bursting. Water Hammer and Mass Oscillation WHAMO software is used in the analysis which uses the implicit finite difference scheme for solving the momentum and continuity equations at unsteady state case. Assiut city water supply network is used in the analysis. Flow of pipe network is studied due to; firstly, the sudden change in water demand at one or more junctions, secondly, the closing of some pipes of the network on the transient pressure and flow rates, and finally the failure in some network pipelines on intrusion or leakage due to transient pressure head fluctuations. The previous cases are studied in steady normal case, without any protection, and under different protection device(s) such as non-return valve and open surge tank. The results showed that rapidly change in demand increases the pressure head and flow rate fluctuations. Closing some pipelines increases pressure in a region and decreases it at another and also changes the direction of flow in the network. Also, failure of some pipelines can cause intrusion and leakage from outside the network to inside and inversely, which affects the values of minimum pressure heads more than the maximum ones. Finally, using of open surge tank with nonreturn valve protects the pipe network effectively from the harm water hammer.
\end{abstract}

Keywords: Water Hammer, Pipes Network, abnormal operation conditions, Assiut city.

\section{Introduction}

Water hammer is the dynamic slam, bang, or shudder that occurs in pipes when a sudden change in fluid velocity creates a significant change in fluid pressure. The name comes from the hammering sound that sometimes occurs during the phenomenon (Parmakian [18]). Water hammer phenomenon has received an attention in the past few decades [5-8, 12, 15 and 20]. Abreu et al. [2] show that the transient behavior is governed by the fluid/pipe characteristics, the inherent boundary characteristic, and one associated characteristic time. Fouzi and Ali [10] studied water hammer in gravity piping system due to sudden closure of valves, using both the most effective numerical methods for discretizing and solving the problem; the finite difference method using WHAMO program and the method of characteristics with software AFT Impulse. They showed that the pressure fluctuations vary dangerously especially in the case of pipes has variable characteristics (section changes with a divergence, a convergence or a bifurcation). Mohamed [16] introduced the effect of the different parameters such as time of valve closure, pipe material rigidity and pipe roughness on the pressure damping. He indicated that the pipe friction factor and the time of valve closing have a significant effect in

\footnotetext{
* Corresponding author.

E-mail address:eng_taftaf82@yahoo.com
} 
Moustafa S. Darweesh et al., Studying of water hammer in water supply pipes network with different abnormal operation conditions (case study-Assiut city network), pp. 2036 - 2054

pressure transient reduction and the elastic pipe such as PVC are better than the rigid pipes in pressure damping. However, his study is restricted to valve closing at the end of pipeline and this case may be differ than the case of water hammer due to pump shut down. Ramos et al. [19] carried out several simulations and experimental tests in order to analyze the dynamic response of single pipelines with different characteristics, such as pipe materials, diameters, thicknesses, lengths and transient conditions. They concluded that being the plastic pipe with a future increasing application, the viscoelastic effect must be considered, either for model calibration, leakage detection or in the prediction of operational conditions (e.g. start up or trip-off electromechanical equipment, valve closure or opening). Samani and Khayatzadeh [21] employed the method of characteristics to analyze transient flow in pipe networks. They applied various numerical tests to examine the accuracy of these methods and found that the method in which the implicit finite difference was coupled with the method of characteristics to obtain the discretized equations is the best compared to the others. Choon et al. [8] investigated the prevention method by installing bypass pipe with non-return valve of water hammer effect. From their experiments, they found that, this prevention method is successfully to reduce the water hammer effect in the pipeline, where the mean pressure is reducing about $33.33 \%$ after installing the prevention method, and this method is most useful in the household usage as the non-return valve. Kim [13] modeled some surge protection devices, such as surge tanks and air chambers, with the impulse response method (IRM) to examine the method of characteristics (MOC). His transient analysis shows that the IRM results match those of simulations of (MOC) in the presence of the hydraulic device. Abozeid et al. [1] investigated the decreasing or increasing the demands at junction through simple pipe network and stated that the change in demand at a simple network junction increases the piezometric head fluctuations and affecting the values and directions of flow rates through the pipes. Ali et al. [3] investigated the influence of existence of a crack in single pipeline on intrusion or leakage due to transient pressure head fluctuation. They reported that, the intrusion and leakage existence reduce the values of the minimum pressure heads more than the maximum pressure heads. Al-Khomairi [4] discussed the use of the steady-state orifice equation for the computation of unsteady leak rates from pipe through crack or rapture. It has been found that the orifice equation gives a very good estimation of the unsteady leak rate history for normal leak openings. Leaks can vary depending on type of soil, water quality, specifications and construction quality, materials, infrastructure age, operation practices and maintenance. Also, leaks can appear as a result of cross-section crack, crushing and longitudinal cracks (Almeida and Ramos [5]). Kirmeyer and Lechevallier [14] state that the leakage rates in water systems range up to 32 percent which indicates that there is a significant connection between the internal system and the external ground. Nixon et al. [17] show that the damping rate method is efficient, easy to apply, and provides a direct solution for leak parameters such as location and size and this method gives promising results for the simple and single pipeline case.

According to the aforementioned studies, it is found that the water hammer in pipes networks has little attention from the investigators. However, every water supply network has its own special characteristics which makes it different from the other networks. Also, due to a lack of field measurements which are costly, it becomes important to use

Journal of Engineering Sciences, Assiut University, Faculty of Engineering, Vol. 41, No. 6, November, 2013, E-mail address: jes@aun.edu.eg 
Moustafa S. Darweesh et al., Studying of water hammer in water supply pipes network with different abnormal operation conditions (case study-Assiut city network), pp. 2036 - 2054

numerical models to gain an indication about the behavior of network under transient effect. Present study is performed to investigate the effect of sudden change of demand in the pipe network, effect of closing some pipes in the network on the transient pressure heads and flow rates and finally, effect of a crack in some pipelines on intrusion or leakage to and from Assiut city water supply network.

\section{Theoretical Considerations}

Because of difficulty in solution of governing equations, engineers in pipelines design usually neglect this phenomenon. Recently, a number of numerical methods suitable for digital computer analyses have been reported in the literature, which may be used to solve these equations (Chaudhry and Yevjevich [7]). In the following, the governing equations are solved by one of these methods.

\subsection{Governing equations for unsteady flow in pipelines}

The governing equations for unsteady flow in pipeline are derived under the following assumptions; (1) one dimensional flow i.e. velocity and pressure are assumed constant at a cross section; (2) the pipe is full and remains full during the transient; (3) no column separation occurs during the transient; (4) the pipe wall and fluid behave linearly elastically; and (5) unsteady friction loss is approximated by steady-state losses.

The unsteady flow inside the pipeline is described in terms of unsteady mass balance (continuity) equation and unsteady momentum equation, which define the state of variables of V (velocity) and $\mathrm{P}$ (pressure) given as Simpson and $\mathrm{Wu}$ [22];

$$
\begin{aligned}
& \frac{\partial \rho}{\partial t}+V \frac{\partial \rho}{\partial x}+\rho \frac{\partial V}{\partial x}+\frac{\rho}{A} \frac{d A}{d t}=0 \\
& \frac{\partial V}{\partial t}+V \frac{\partial V}{\partial x}+\frac{1}{\rho} \frac{\partial P}{\partial x}-g \sin \alpha+\frac{f|V| V}{2 D}=0
\end{aligned}
$$

Where $\mathrm{x}=$ distance along the pipeline; $\mathrm{t}=$ time; $\mathrm{V}=$ velocity; $\mathrm{P}=$ hydraulic pressure in the pipe; $\mathrm{g}=$ acceleration due to gravity; $\mathrm{f}=$ Darcy-Weisbach friction factor; $\rho=$ fluid density; $\mathrm{D}=$ pipe diameter; $\alpha=$ pipe slope angle, and $\mathrm{A}=$ cross sectional area of the pipe.

Equation (1) is the continuity equation and takes into account the compressibility of water and the flexibility of pipe material. Equation (2) is the equation of motion. In Eq. (1), the terms $\frac{1}{\rho}\left(\frac{\partial \rho}{\partial t}+\frac{\partial \rho}{\partial x} V\right)$ are replaced by equivalent $\frac{1}{\rho} \frac{d \rho}{d t}$ where $V=\frac{d x}{d t}, \frac{d \rho}{d t}=\frac{\rho}{K} \frac{d P}{d t}$, and $\mathrm{K}$ is the bulk modulus of the fluid. Also, the fourth term in Eq. (1) can be expressed as $\left(1-v^{2}\right) \frac{\rho D}{e E} \frac{d P}{d t}$, where $v$ is the poison's ratio of the pipe, e is the pipe wall thickness and $\mathrm{E}$ is the Young's modulus of elasticity of the pipe. Substitution by these abbreviations in Eq. (1), it can be reduced to the following formula;

$$
\frac{d P}{d t}\left[\frac{1}{K}+\left(\frac{1-v^{2}}{E}\right) \frac{D}{e}\right]+\frac{\partial V}{\partial x}=0
$$

Wave speed can be defined as the time taken by the pressure wave generated by instantaneous change in velocity to propagate from one point to another in a closed conduit. Wave speed (c) can be expressed as;

Journal of Engineering Sciences, Assiut University, Faculty of Engineering, Vol. 41, No. 6, November, 2013, E-mail address: jes@aun.edu.eg 
Moustafa S. Darweesh et al., Studying of water hammer in water supply pipes network with different abnormal operation conditions (case study-Assiut city network), pp. 2036 - 2054

$\frac{1}{\rho c^{2}}=\left[\frac{1}{K}+\left(\frac{1-v^{2}}{E}\right) \frac{D}{e}\right]=\frac{1}{K}\left[1+\frac{K c_{1} D}{E e}\right]$

Where: $C_{1}=\left(1-v^{2}\right)$. Substitution by Eq. (4) into Eq. (3) and dividing the result by $\gamma$ yields;

$\left[\frac{\partial H}{\partial t}+\frac{\partial H}{\partial x} V\right]+\frac{c^{2}}{g} \frac{\partial V}{\partial x}=0$

Where $\mathrm{H}$ is the piezometric head, i.e. pressure head plus the elevation head. The term $\frac{\partial H}{\partial x}$ is small compared to $\frac{\partial H}{\partial t}$ and it is often neglected. Thus, the simplified form of the continuity equation in terms of discharge, [Eq. (5)] becomes;

$\frac{\partial H}{\partial t}+\frac{\partial Q}{\partial x} \frac{c^{2}}{g A}=0$

By the same way, the momentum equation, i.e. Eq. (2) can be simplified and written in terms of discharge and piezometric head as follows;

$\frac{\partial H}{\partial x}+\frac{1}{g A} \frac{\partial Q}{\partial t}+\frac{f Q|Q|}{2 g D A^{2}}=0$

\subsection{Implicit finite difference solution method}

The implicit finite difference method is a numerical method which can be used for solving water hammer equations. The computer program WHAMO uses the implicit finitedifference technique but converts its equations to a linear form before it solves the set of equations (Fitzgerald and Van Blaricum [9]).

The solution space is discretized into the $\mathrm{x}$-t plane, so that at any point on the grid $(\mathrm{x}, \mathrm{t})$ there is a certain $\mathrm{H}$ and $\mathrm{Q}$ for that point, $\mathrm{H}(\mathrm{x}, \mathrm{t})$ and $\mathrm{Q}(\mathrm{x}, \mathrm{t})$ as shown in Fig. (1).

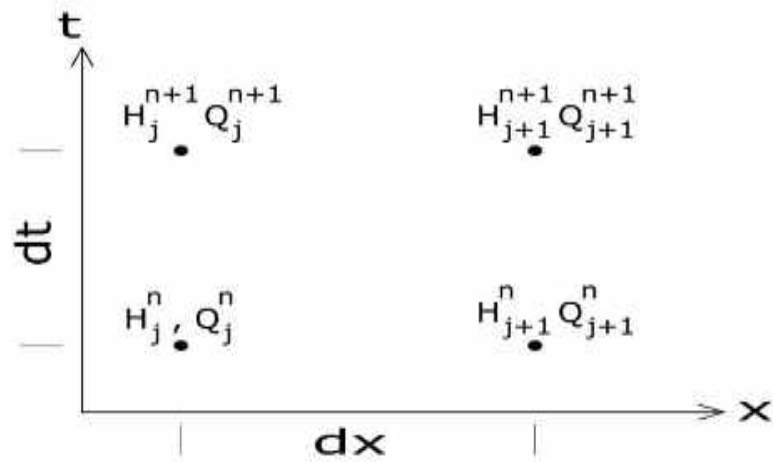

Fig. 1. The finite difference grid

The momentum equation and the continuity equation can be represented in a short form by introducing the following coefficients for the known values in a system;

$\alpha_{j}=\frac{2 \Delta t c_{j}^{2} \theta}{g A_{j} \Delta x_{j}}$

Journal of Engineering Sciences, Assiut University, Faculty of Engineering, Vol. 41, No. 6, November, 2013, E-mail address: jes@aun.edu.eg 
Moustafa S. Darweesh et al., Studying of water hammer in water supply pipes network with different abnormal operation conditions (case study-Assiut city network), pp. 2036 - 2054

$$
\begin{aligned}
& \beta_{j}=\left(H_{n, j+1}+H_{n, j}\right)+\frac{(1-\theta)}{\theta} \alpha_{j}\left(Q_{n, j}-Q_{n, j+1}\right) \\
& \gamma_{j}=\frac{\Delta x_{j}}{2 g \theta A_{j} \Delta t} \\
& \delta_{j}=\frac{(1-\theta)}{\theta}\left(H_{n, j}-H_{n, j+1}\right)+\gamma_{j}\left(Q_{n, j}+Q_{n, j+1}\right) \\
& \quad-\frac{\Delta x_{j} f_{j}}{4 g \theta D_{j} A_{j}^{2}}\left(Q_{n, j}\left|Q_{n, j}\right|+Q_{n, j+1}\left|Q_{n, j+1}\right|\right)
\end{aligned}
$$

Where $\theta$ is a weighing factor included for numerical stability. All parameters for the coefficients should be known from the properties of the pipe or the values of head and flow at the previous time step. With the coefficients, the momentum and continuity equations of the $\mathrm{j}^{\text {th }}$ segment of the pipe become as given by Batterton [6] as follows;

$$
\begin{aligned}
& \text { Momentum: }-H_{n, j+1}+H_{n+1, j+1}+\gamma_{j}\left(Q_{n+1, j}+Q_{n+1, j+1}\right)=\delta_{j} \\
& \text { Continuity: } H_{n, j+1}+H_{n+1, j+1}+\alpha_{j}\left(Q_{n+1, j+1}-Q_{n+1, j}\right)=\beta_{j}
\end{aligned}
$$

Now, with equations for the all links and nodes in the system, the initial and boundary conditions, a matrix of the linear system of equations can be set up to solve for head and flow everywhere, simultaneously, for the first time step. The process is repeated for the next time step, and again for the next step until the specified end of the simulation.

\section{Case Study}

The analysis of transient flow was performed for Assiut city water supply network (ACWSN). There are two sources of water feeding the network, from which the water is pumped into the network, at node 27 and node 28. Elevations of all the network junctions are assumed to be the same at level zero. Average base demands for the different junction nodes are shown in Table (1). The distribution system shown in Fig. (2) is composed of 29.6 Km of different diameter pipelines with lengths of P1 through P35 as shown in Table (2). Shown in Fig. (2) are the pipe and joint numbering Pi and Ji respectively and also, the flow directions for normal operation conditions. All pipes are High Density Polyethylene (HDPE) and the head loss in each pipe is computed using Darcy-Weisbach formula. The results are performed for three parts; the first, is studying the sudden change in water demand at one or more junctions, the second, is investigating the closing of some pipes of the network on the transient pressure and flow rates and finally, the intrusion and leakage to and from the pipe network were studied. The three parts are studied with normal operation conditions (pumps 36 and 37 working normally), without any protection against water hammer phenomenon, and are studied with a transient protection device(s) such as non-return valve and open surge tank.

Journal of Engineering Sciences, Assiut University, Faculty of Engineering, Vol. 41, No. 6, November, 2013, E-mail address: jes@aun.edu.eg 
Moustafa S. Darweesh et al., Studying of water hammer in water supply pipes network with different abnormal operation conditions (case study-Assiut city network), pp. 2036 - 2054

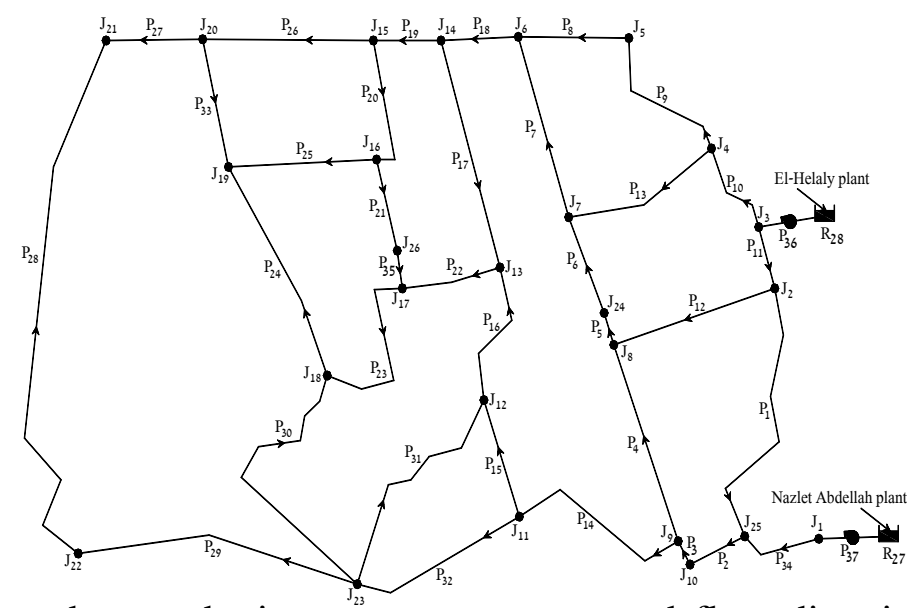

Fig. 2. Pipes, nodes numbering, pumps, sources and flow directions for normal operation condition of Assiut pipe network for pumps 36 and 37

\section{Table 1.}

Average base demands for the different junction nodes.

\begin{tabular}{|c|c|c|c|c|c|c|c|c|c|c|c|c|c|}
\hline Node number & 1 & 2 & 3 & 4 & 5 & 6 & 7 & 8 & 9 & 10 & 11 & 12 & 13 \\
\hline $\begin{array}{c}\text { Average base } \\
\text { demand } \\
\text { (Lit./s) }\end{array}$ & 0.0 & 72 & 0.0 & 72 & 44 & 44 & 72 & 64 & 33 & 33 & 64 & 98 & 86 \\
\hline Node number & 14 & 15 & 16 & 17 & 18 & 19 & 20 & 21 & 22 & 23 & 24 & 25 & 26 \\
\hline $\begin{array}{c}\text { Average base } \\
\text { demand } \\
\text { (Lit./s) }\end{array}$ & 44 & 19 & 33 & 72 & 109 & 72 & 53 & 90 & 90 & 127 & 0.0 & 44 & 0.0 \\
\hline
\end{tabular}

Table 2.

Lengths and diameters of the different pipes.

\begin{tabular}{|c|c|c|c|c|c|}
\hline $\begin{array}{c}\text { Pipe } \\
\text { number }\end{array}$ & $\begin{array}{c}\text { Length } \\
(\mathbf{m})\end{array}$ & $\begin{array}{c}\text { Diameter } \\
(\mathbf{m m})\end{array}$ & $\begin{array}{c}\text { Pipe } \\
\text { number }\end{array}$ & $\begin{array}{c}\text { Length } \\
(\mathbf{m})\end{array}$ & $\begin{array}{c}\text { Diameter } \\
(\mathbf{m m})\end{array}$ \\
\hline P1 & 1600 & 800 & P19 & 300 & 600 \\
\hline P2 & 300 & 1000 & P20 & 600 & 400 \\
\hline P3 & 600 & 1000 & P21 & 300 & 500 \\
\hline P4 & 900 & 500 & P22 & 600 & 400 \\
\hline P5 & 200 & 500 & P23 & 600 & 400 \\
\hline P6 & 300 & 500 & P24 & 950 & 400 \\
\hline P7 & 1400 & 500 & P25 & 950 & 300 \\
\hline P8 & 1100 & 800 & P26 & 1200 & 600 \\
\hline P9 & 500 & 800 & P27 & 400 & 600 \\
\hline
\end{tabular}

Journal of Engineering Sciences, Assiut University, Faculty of Engineering, Vol. 41, No. 6, November, 2013,E-mail address: jes@aun.edu.eg 
Moustafa S. Darweesh et al., Studying of water hammer in water supply pipes network with different abnormal operation conditions (case study-Assiut city network), pp. 2036 - 2054

\begin{tabular}{|c|c|c|c|c|c|}
\hline $\begin{array}{c}\text { Pipe } \\
\text { number }\end{array}$ & $\begin{array}{c}\text { Length } \\
(\mathbf{m})\end{array}$ & $\begin{array}{c}\text { Diameter } \\
(\mathbf{m m})\end{array}$ & $\begin{array}{c}\text { Pipe } \\
\text { number }\end{array}$ & $\begin{array}{c}\text { Length } \\
(\mathbf{m})\end{array}$ & $\begin{array}{c}\text { Diameter } \\
(\mathbf{m m})\end{array}$ \\
\hline P10 & 800 & 800 & P28 & 2650 & 600 \\
\hline P11 & 150 & 800 & P29 & 2100 & 600 \\
\hline P12 & 850 & 500 & P30 & 1500 & 400 \\
\hline P13 & 1100 & 500 & P31 & 1600 & 400 \\
\hline P14 & 500 & 1000 & P32 & 1500 & 800 \\
\hline P15 & 750 & 500 & P33 & 700 & 400 \\
\hline P16 & 850 & 500 & P34 & 500 & 1200 \\
\hline P17 & 1000 & 500 & P35 & 150 & 500 \\
\hline P18 & 100 & 800 & & & \\
\hline
\end{tabular}

\section{Results and Discussions}

\subsection{Influence of decreasing demand time on pressure head and pipe flow rate:}

Sudden change of water demand at one point or more of a pipe network such as hydrant flushing, fire fighting, sudden closing or sudden opening of valves causes a large variation of energy head at different points of the network, whatever the cause, it is very important to simulate this common occurrence to determine whether dangerous pressure developed or not. Figures ( 3 to 5) show the variation of piezometric head with time at different nodes after decreasing the demand at junctions $\mathrm{J} 23, \mathrm{~J} 17$, and $\mathrm{J} 25$ from the steady state values to zero. From the figures, it is noticeable that the pressure head fluctuations depends on the point initial demand value, where J23 $(128 \mathrm{~L} / \mathrm{sec}$.) has large pressure fluctuations than all points, although point $\mathrm{J} 25(45 \mathrm{~L} / \mathrm{sec}$.) it is the nearest point from the pumps. Also, it can be seen that the positive deviation in pressure head is larger than the steady case than the negative one and the most affected points by changing of demand are the nearest points from place of variation and the most far point has the less effect. For examples, the sudden change of water demand at joint $\mathbf{J} 23$ increases the pressure head by 4.8, 4.4, 3.8 and $1.2 \%$ from their steady state head at joints $\mathrm{J} 23, \mathrm{~J} 22$, J17 and $\mathrm{J} 25$, respectively.

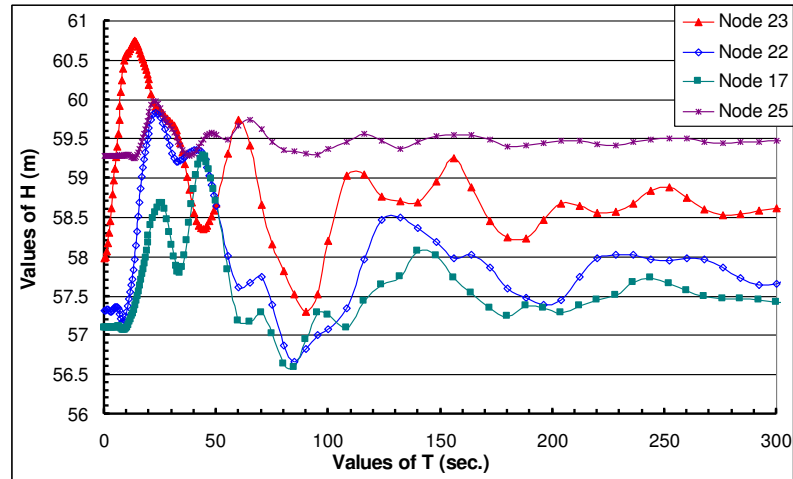

Fig. 3. Changes of pressure heads with time at different nodes due to the sudden decreasing of demand at junction $\mathrm{J} 23$

Journal of Engineering Sciences, Assiut University, Faculty of Engineering, Vol. 41, No. 6, November, 2013, E-mail address: jes@aun.edu.eg 
Moustafa S. Darweesh et al., Studying of water hammer in water supply pipes network with different abnormal operation conditions (case study-Assiut city network), pp. 2036 - 2054

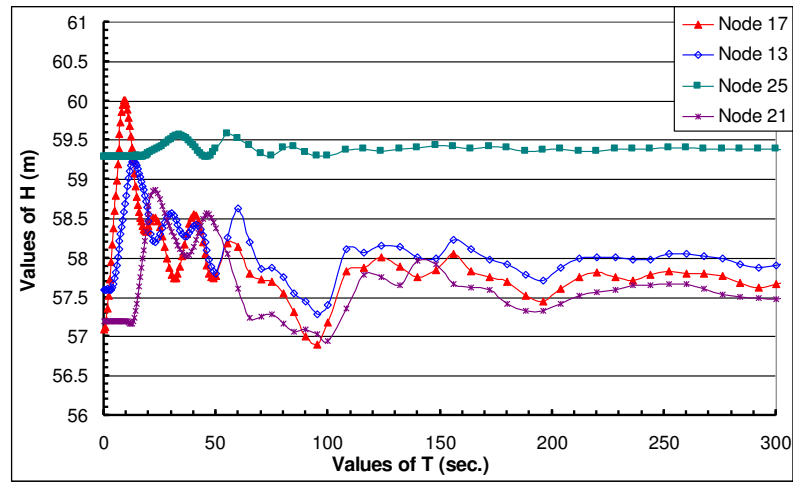

Fig. 4. Changes of pressure heads with time at different nodes due to the sudden decreasing of demand at junction $\mathrm{J} 17$.

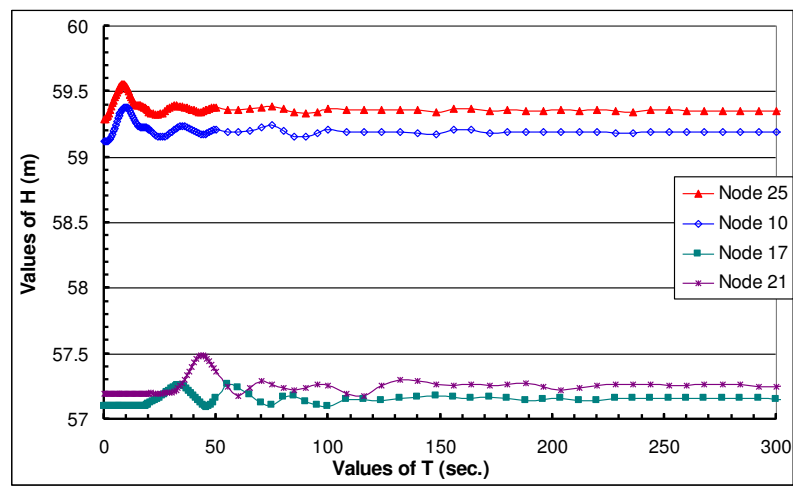

Fig. 5. Changes of pressure heads with time at different nodes due to the sudden decreasing of demand at junction $\mathrm{J} 25$.

To study the effect of the sudden change of water demand at junctions J23, J17 and J25 from the steady state values to zero, on discharge variations with time through different pipelines, Figs. (6, 7 and 8) are drawn. It is seen from the Figs. that, there is no change in flow direction and the fluctuations in flow rate increase through pipes near from point of demand variation but the most affected pipeline by demand change that has high normal steady discharge. Also, the flow fluctuations through the pipes network increase as the joint initial demand value increases.

Journal of Engineering Sciences, Assiut University, Faculty of Engineering, Vol. 41, No. 6, November, 2013, E-mail address: jes@aun.edu.eg 
Moustafa S. Darweesh et al., Studying of water hammer in water supply pipes network with different abnormal operation conditions (case study-Assiut city network), pp. 2036 - 2054

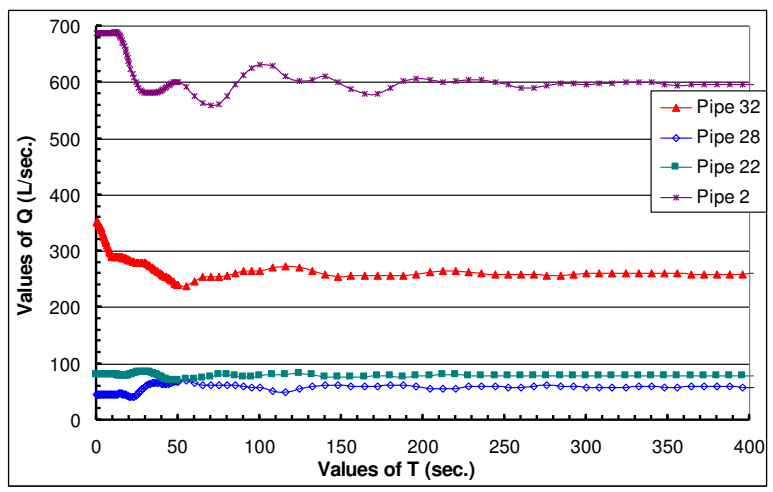

Fig. 6. Changes of discharges through different pipes with time due to the sudden decreasing of demand at junction $\mathrm{J} 23$

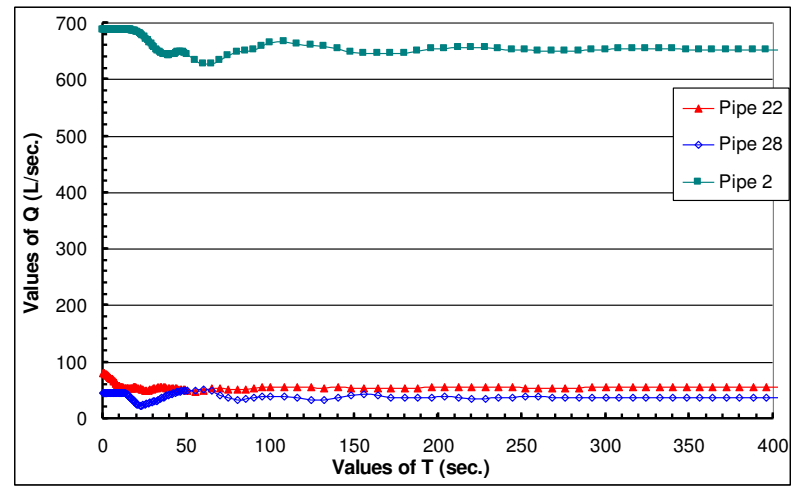

Fig. 7. Changes of discharges through different pipes with time due to the sudden decreasing of demand at junction $\mathrm{J} 17$

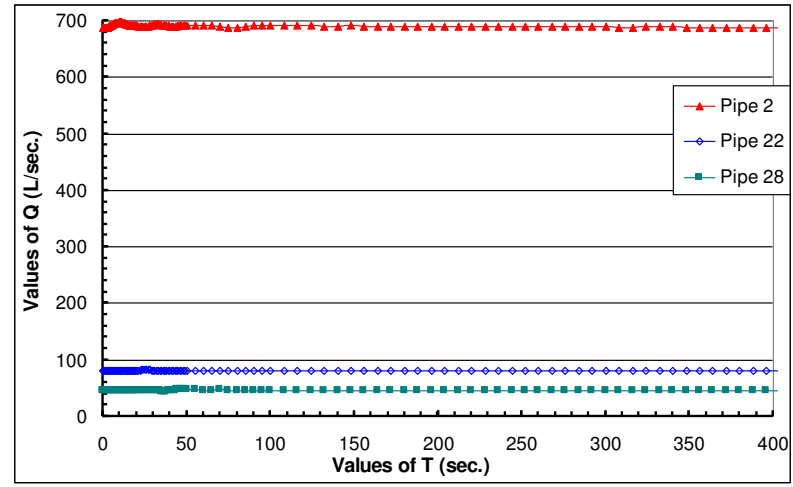

Fig. 8. Changes of discharges through different pipes with time due to the sudden decreasing of demand at junction $\mathrm{J} 25$

Journal of Engineering Sciences, Assiut University, Faculty of Engineering, Vol. 41, No. 6, November, 2013, E-mail address: jes@aun.edu.eg 
Moustafa S. Darweesh et al., Studying of water hammer in water supply pipes network with different abnormal operation conditions (case study-Assiut city network), pp. 2036 - 2054

To investigate the influence of using protection devices on water hammer phenomenon due to the sudden change of water demand, Figs. 9 and 10 are drawn. The figures show the transient pressure heads and discharges with time at joint J23 and pipe P32, respectively due to the sudden change in demand at J23 and using non-return valve (NRV) only and using NRV with open surge tank. It is noticeable from the Figs. that the protection devices do not have a significant effect in both pressure heads and flow rates. This because the change in pressure head more than the normal head is very small compared to the pumps shut down, (maximum increase in the head at $\mathrm{J} 23$ is $4.8 \%$ ).

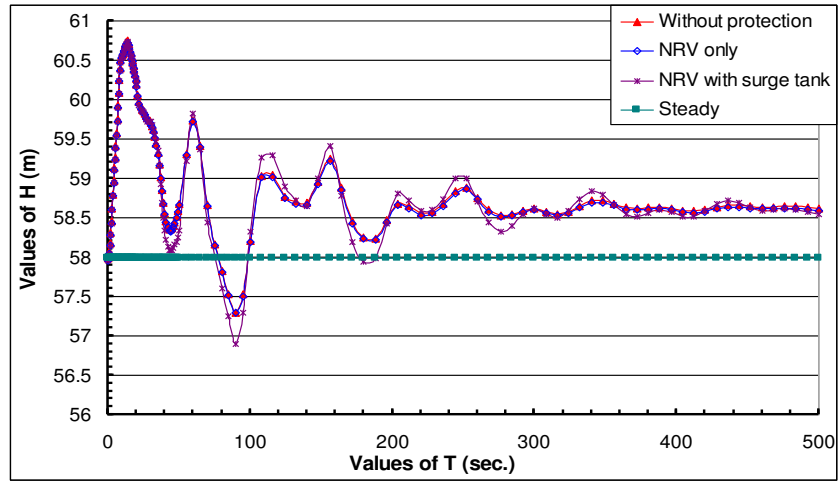

Fig. 9. Changes of pressure heads with time at node $\mathrm{J} 23$ due to the sudden decreasing of demand at junction $\mathrm{J} 23$ and using different protection methods

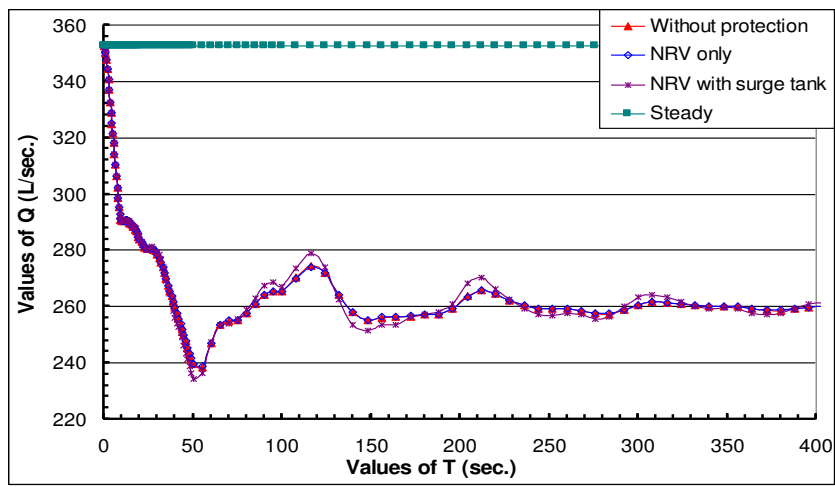

Fig. 10. Changes of discharges through pipe P32 with time due to the sudden decreasing of demand at junction $\mathrm{J} 23$ and using different protection methods.

\subsection{Influence of closing some pipes on pressure head and pipe flow rate:}

Planned (e.g., regular maintenance) and unplanned (e.g., pipe burst) interruptions occur regularly in water distribution systems leading to their reduced performance (Giustolisi et al. [11]). To show the effect of closing some pipes on transient pressure heads and flow rates in Assiut city water supply network (ACWSN), the piezometric head variations and flow rates with time at different junctions and pipes are discussed in this

Journal of Engineering Sciences, Assiut University, Faculty of Engineering, Vol. 41, No. 6, November, 2013, E-mail address: jes@aun.edu.eg 
Moustafa S. Darweesh et al., Studying of water hammer in water supply pipes network with different abnormal operation conditions (case study-Assiut city network), pp. 2036 - 2054

section. Figures 11 and 12 show the variations of pressure heads with time at different nodes due to closing pipes P18 and P14, respectively. It is noticeable that, for the nodes after the closed pipes, the pressure head is reduced more than those nodes before this pipe. This because that after closing the pipe, the water behaves other paths which leads to that water enters to the point after closing the pipe instead of exist from it. Whereas, the liquid moves from the high to low pressure, that leads to the high reduction in the pressure heads than that in nodes before the closed pipeline. Comparing these results with those for case of normal operation conditions are shown in Figs. 13 and 14, one can see that the pressure heads at point $\mathrm{J} 14$ reduced from -22 and $+58 \mathrm{~m}$ before closing pipe P18 to -41 and $+52 \mathrm{~m}$ after closing same pipe, while at point $\mathrm{J} 11$ it decreased from -21 and $+59 \mathrm{~m}$ to -38 and +47 $\mathrm{m}$ of water before and after closing pipe P14. Also, for protecting the network by using NRV with open surge tank, they absorb the water hammer without any fluctuations to reach the final stable pressure head.

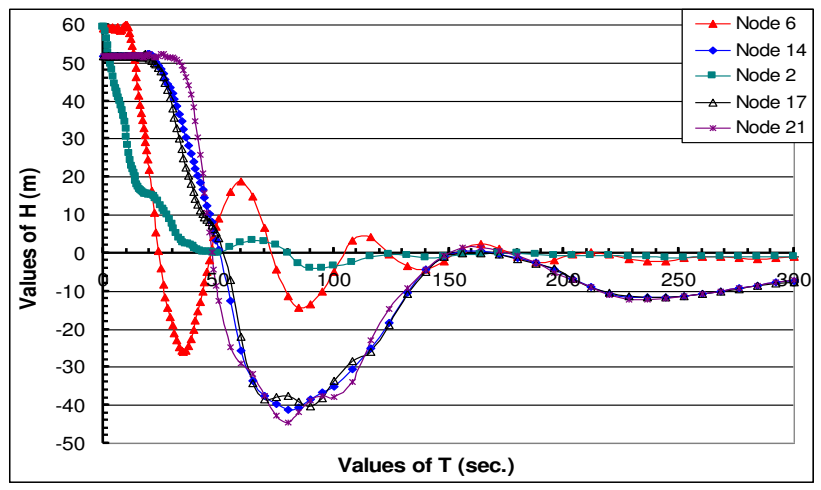

Fig. 11. Changes of pressure heads with time at different nodes due to the closing of pipe $\mathrm{P} 18$

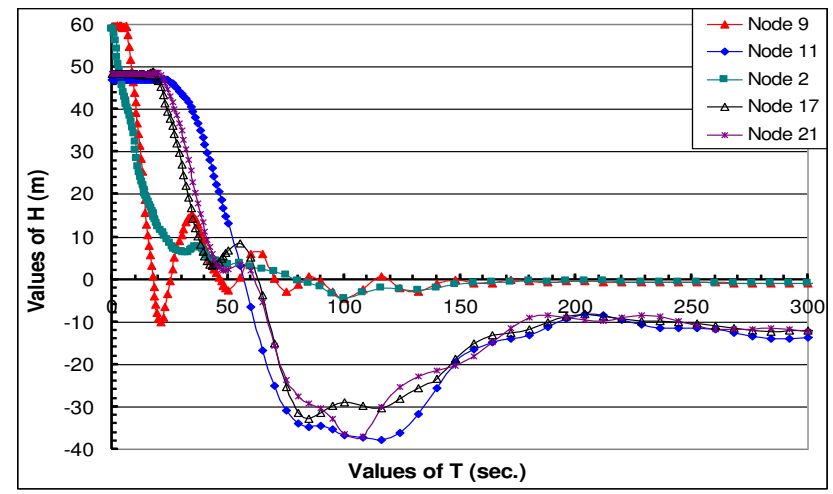

Fig. 12. Changes of pressure heads with time at different nodes due to the closing of pipe $\mathrm{P} 14$

Journal of Engineering Sciences, Assiut University, Faculty of Engineering, Vol. 41, No. 6, November, 2013, E-mail address: jes@aun.edu.eg 
Moustafa S. Darweesh et al., Studying of water hammer in water supply pipes network with different abnormal operation conditions (case study-Assiut city network), pp. 2036 - 2054

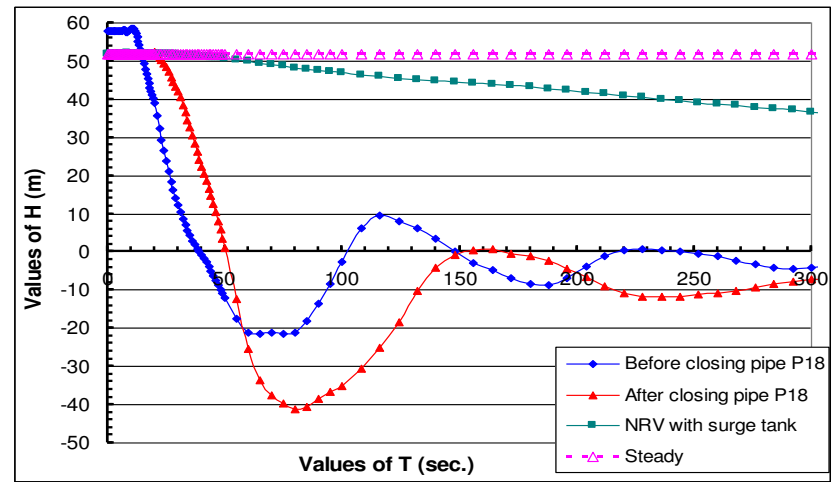

Fig. 13. Changes of pressure heads with time at node J14 before and after closing pipe $\mathrm{P} 18$

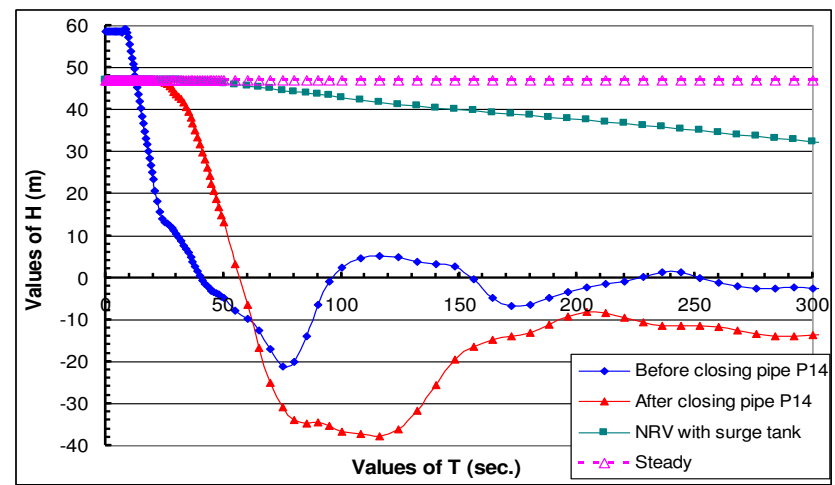

Fig. 14. Changes of pressure heads with time at node J11 before and after closing pipe $\mathrm{P} 14$

Shown in Figs. 15 and 16 are the plots of transient flow rates through different pipes with time due to the closing of pipelines P18 and P14, respectively. The plots revealed that, the closing some pipes in the network may have a large effect on the network flow regime (value and direction), especially for the pipelines besides the closed pipes and that pipes surrounding by the paths that water may take. For purpose of comparison, between the results of the case with pipe closed and those without closing, the transient flow rates against the time are plotted as in Figs. 17 and 18, a large flow fluctuations and a variation in flow directions are noticed. For instance, the transient flow through pipe P14 increases from $1383 \mathrm{~L} / \mathrm{sec}$. before closing pipe P18 to $1692 \mathrm{~L} / \mathrm{sec}$. after closing the same pipe, but for pipe P17, it reverses its direction from +163 to $-218 \mathrm{~L} / \mathrm{sec}$. While for closing Pipe P14, the discharge through P18 increases from $944 \mathrm{~L} / \mathrm{sec}$. for normal operation to $1390 \mathrm{~L} / \mathrm{sec}$. after closing P14, and reverses its direction through pipe P32 from -507 to $-72 \mathrm{~L} / \mathrm{sec}$. before and after closing pipe P14. Hence, these variations in directions and high flow fluctuations may have great effect on water quantity and quality at different locations along the pipe network. Also, for using NRV with surge tank, the discharge values and direction remain close to the values of steady operation without any waves or fluctuations, and it is

Journal of Engineering Sciences, Assiut University, Faculty of Engineering, Vol. 41, No. 6, November, 2013, E-mail address: jes@aun.edu.eg 
2048

Moustafa S. Darweesh et al., Studying of water hammer in water supply pipes network with different abnormal operation conditions (case study-Assiut city network), pp. 2036 - 2054

observed from all the previous figures, that the closing pipe P18 has a large effect on the pressure heads and flow fluctuations than closing pipe P14.

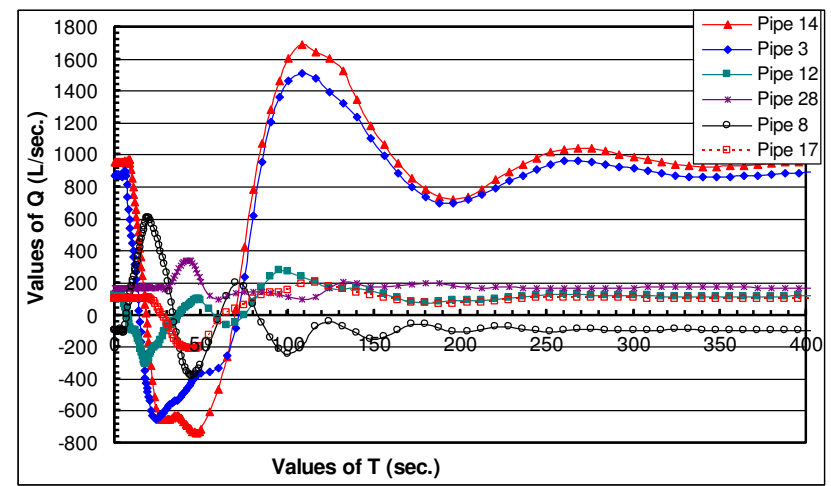

Fig. 15. Changes of discharges through different pipes with time due to the closing of pipe P18

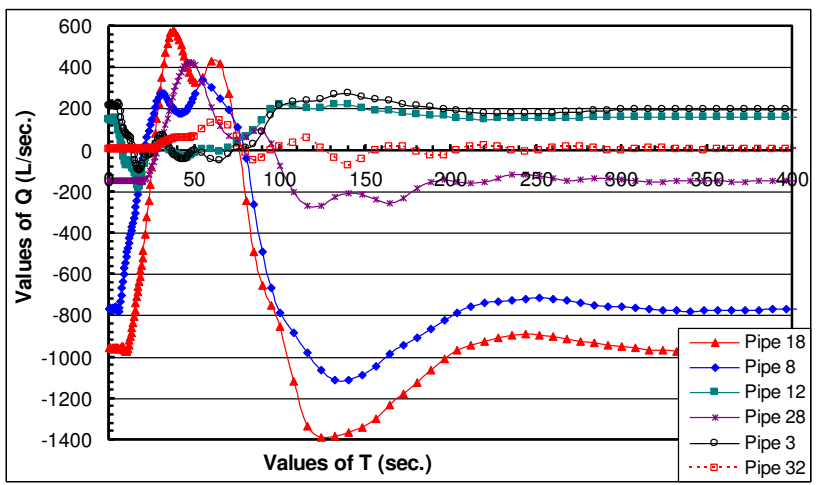

Fig. 16. Changes of discharges through different pipes with time due to the closing of pipe P14

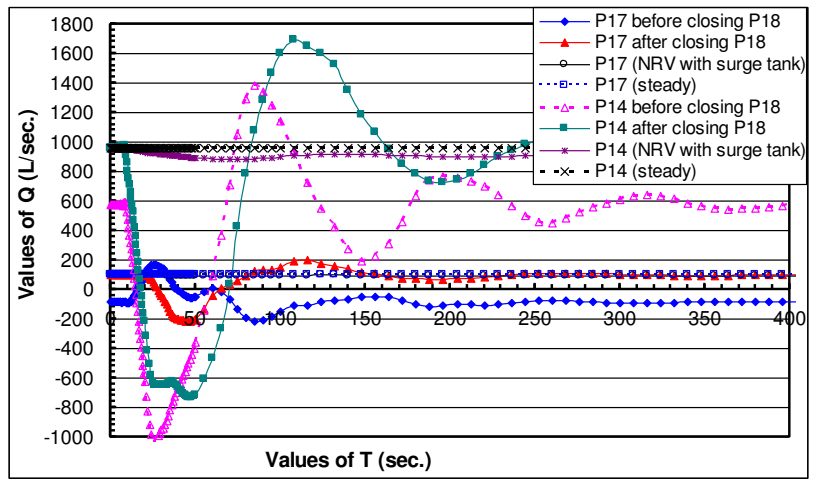

Fig. 17. Changes of discharges through pipes P17 and P14 with time before and after closing pipe P18

Journal of Engineering Sciences, Assiut University, Faculty of Engineering, Vol. 41, No. 6, November, 2013, E-mail address: jes@aun.edu.eg 
Moustafa S. Darweesh et al., Studying of water hammer in water supply pipes network with different abnormal operation conditions (case study-Assiut city network), pp. 2036 - 2054

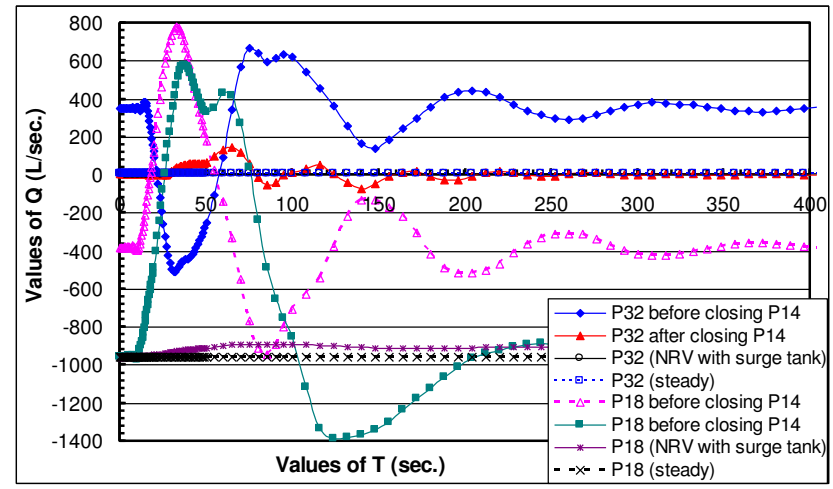

Fig. 18. Changes of discharges through pipes $\mathrm{P} 32$ and $\mathrm{P} 18$ with time before and after closing pipe $\mathrm{P} 14$

\subsection{Influence of failure of some pipes on water hammer phenomenon:}

Water project engineers need to assess and monitor the vulnerability of water distribution network to component failures, couple this with an estimate of the likelihood of these failures, thus providing a measure of the reliability of supply. This needs stems from statutory and contractual obligations in respect of the level of service offered to consumers/customers.

A failure of the pipe network is assumed to be at nodes $\mathrm{J} 18$ and $\mathrm{J} 19$, the minimum and maximum pressure heads due to the sudden shut down of pumps 36 and 37 together, are $39.59,58 \mathrm{~m}$ and -39.15 and $57.66 \mathrm{~m}$ for points 18 and 19 , respectively.

\subsubsection{Intrusion and leakage:}

To study the influence of intrusion and leakage on transient pressure heads and flow rates, the underground water level assumes to be between -39.59 and $58 \mathrm{~m}$, the water direction will be from the underground water to the pipe network and reverse. Flow of pipe network is studied under steady normal case, without connection between outside and inside the pipelines, intrusion and leakage were allowed and the underground water level is the average $(1.0 \mathrm{~m})$ and finally a non-return valve with open surge tank are added to investigate its effect on protection of the network from the water hammer. Figures 19 and 20 show the variations in maximum and minimum piezometric heads along certain path (23-18-19-20) for the mentioned studied cases. Figure 19 shows that intrusion or leakage between inside and outside the supply network reduces the maximum pressure heads, along the specified path, for instance at J18, J19 and J20 by nearly 1.9, 1.2 and $1.2 \%$ respectively. On the other side, it has a significant effect on the minimum pressure heads (less than intrusion only or leakage only), where it decreases at nodes J23, J18, J19 and J20 by $153,166,165$ and $162 \%$ from their steady heads as shown in Fig. 20. This may due to the ground water elevation that is less or more than the pressure head inside the pipe network and hence, the water moves from the higher pressure to the lower one that leads to decreases the positive and negative pressures inside the pipelines. Also, the most affected points by the intrusion and leakage are the nearest points from the existing crack, and for Journal of Engineering Sciences, Assiut University, Faculty of Engineering, Vol. 41, No. 6, November, 2013, E-mail address: jes@aun.edu.eg 
Moustafa S. Darweesh et al., Studying of water hammer in water supply pipes network with different abnormal operation conditions (case study-Assiut city network), pp. 2036 - 2054

protecting the network by using NRV with open surge tank, they absorb the water hammer without any waves and the minimum pressure heads not reached to negative values.

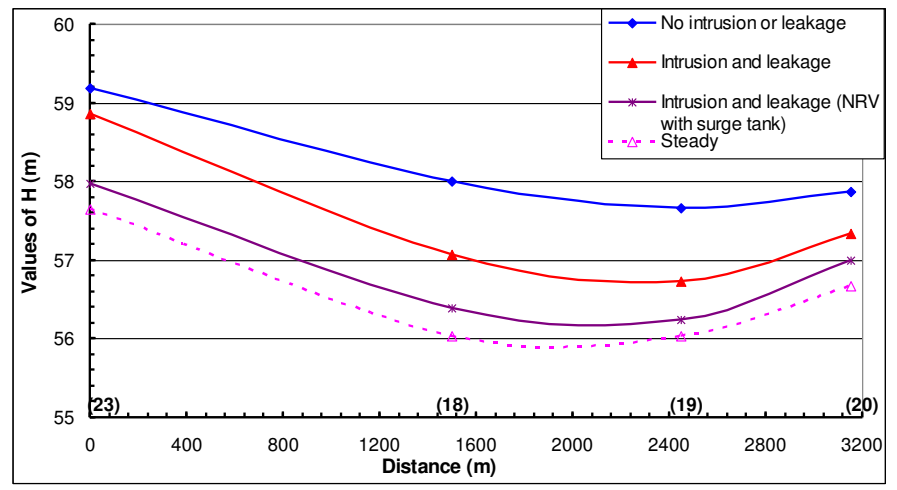

Fig. 19. Maximum piezometric heads along the path (23-18-19-20) due to the closing of pumps 36 and 37 together, intrusion and leakage existence

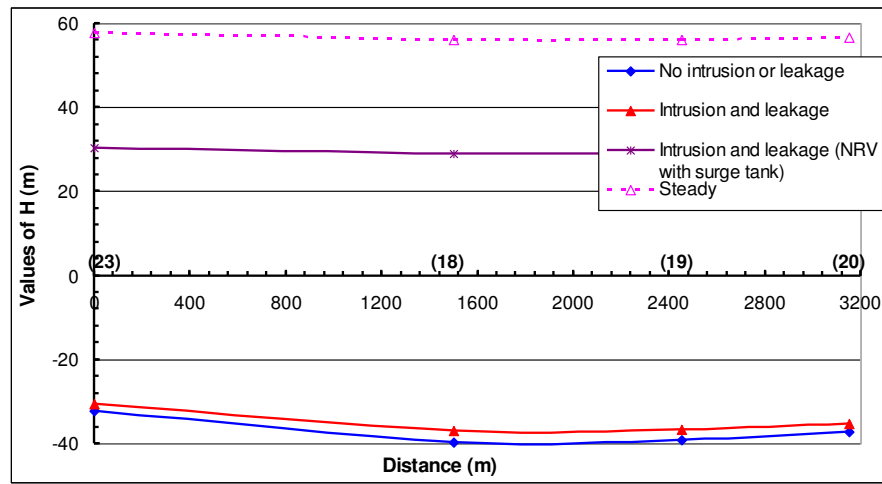

Fig. 20. Minimum piezometric heads along the path (23-18-19-20) due to the closing of pumps 36 and 37 together, intrusion and leakage existence.

Figures (21 and 22) show the variations of flow rates through pipes P23 and P12 with the time for the previous cases of study. Steady normal operations are included for the comparison. Negative sign means that the discharge is in the reverse direction in comparison with that of normal operation conditions. In comparison between the results of the case without connection between inside and outside the supply network and those with intrusion and leakage, it appears that decreases both positive and negative deviation than the steady discharge and the most affected pipeline by the effect of the surrounding ground water is pipe P23 where, the discharge decreases its positive and negative values from +164 to $+145 \mathrm{~L} / \mathrm{sec}$. and from -129 to $-105 \mathrm{~L} / \mathrm{sec}$. While for the outermost pipelines from the crack (P12) there is no noticeable change in the discharge before and after the intrusion and leakage. Also, one can see from the figures, for using NRV with surge tank to safeguard the pipe network from the water hammer harm, the discharge values and direction remain close to the values of steady operation and the deviation in the discharge

Journal of Engineering Sciences, Assiut University, Faculty of Engineering, Vol. 41, No. 6, November, 2013, E-mail address: jes@aun.edu.eg 
Moustafa S. Darweesh et al., Studying of water hammer in water supply pipes network with different abnormal operation conditions (case study-Assiut city network), pp. 2036 - 2054

from the normal case is harmony to reach the final steady value without any waves or fluctuations.

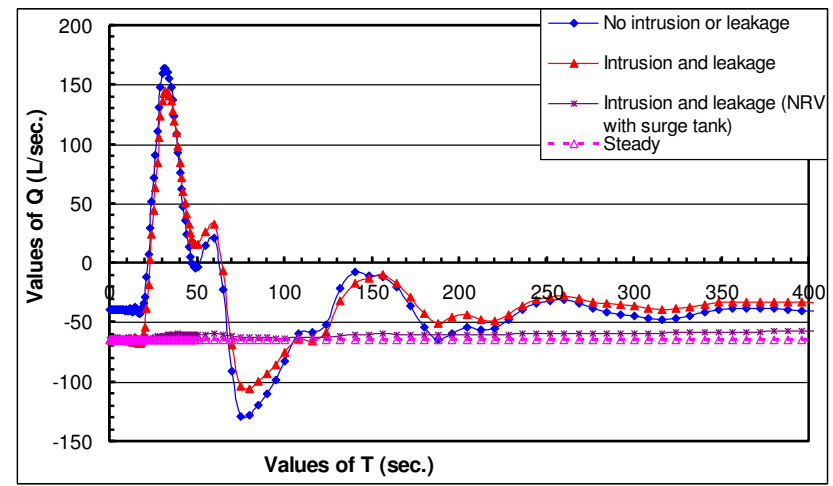

Fig. 21. Changes of discharges through pipe P23 with time due to the closing of 36 and 37 together, intrusion and leakage existence

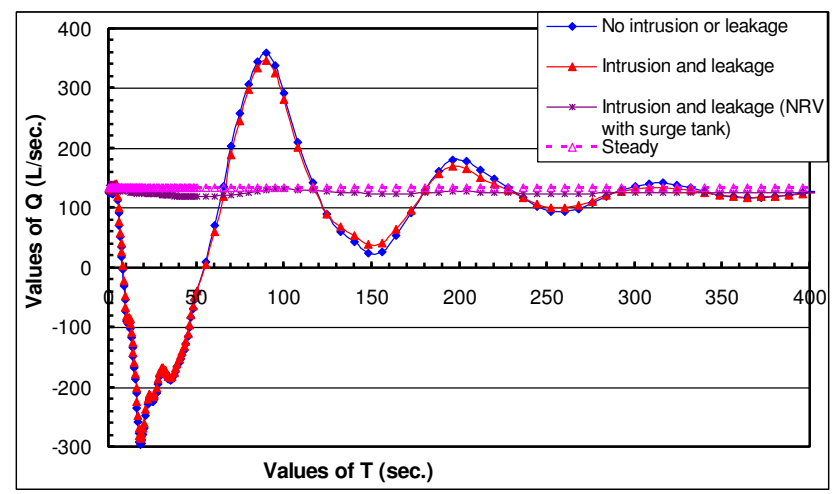

Fig. 22. Changes of discharges through pipe P12 with time due to the closing of pumps 36 and 37 together, intrusion and leakage existence.

\section{Conclusions}

Based on the numerical results of WHAMO program for transient flow in Assiut city water supply network with the studied scenarios, it is found that:

1. Sudden change in demand at a junction through pipe networks increases the pressure head and flow rate fluctuations, these changes in pressures and discharges must be taken into considerations for network safety.

2. Closing of some pipelines in the pipe network not only increases the pressure head in region and decreases it at another, but also changes the flow directions in some pipes.

3. Occurrence of water hammer phenomenon in pipe system may cause intrusion of contaminant water from outside the pipeline, if crack exist in it.

4. Intrusion and leakage existence affect the values of minimum pressure heads more than the maximum pressure heads.

Journal of Engineering Sciences, Assiut University, Faculty of Engineering, Vol. 41, No. 6, November, 2013, E-mail address: jes@aun.edu.eg 
Moustafa S. Darweesh et al., Studying of water hammer in water supply pipes network with different abnormal operation conditions (case study-Assiut city network), pp. 2036 - 2054

5. Using non-return valve with open surge tank protects the pipe network from negative pressures as well as high pressures and high flow fluctuations.

\section{References}

[1] Abozeid, G., Mohamed, H. I., and Hassan, I. M., "Studying of Water Hammer Phenomenon Caused by Sudden Variation of Water Demand at Water Supply Pipes Network", Jour. of Eng. Science, Assiut University, Vol. 40, No. 2, March, pp. 353366, (2012).

[2] Abreu, J., Cabrera, E., Izquierdo, J. and Garcia-Serra J., "Flow Modeling in Pressurized Systems Revisited”, J. Hydr. Engrg., Vol. 125, Issue 11, pp. 1154-1169, (1999).

[3] Ali, N.A., Mohamed, H.I., El-Darder, M.E., and Mohamed, A.A., "Analysis of transient flow phenomenon in pressurized pipes system and methods of protection", Jour. of Eng. Science, Assiut University, Vol. 38, No. 2, pp. 323-342, (2010).

[4] Al-Khomairi, A. M., "Use of the Steady-State Orifice Equation in the Computation of Transient Flow Through Pipe Leaks", The Arabian Jour. for science and Eng., Vol. 30, N. IB, pp. 33-45, (2005).

[5] Almeida A. B., and Ramos H. M., "Water supply operation: diagnosis and reliability analysis in a Lisbon pumping system", Journal of Water Supply: Research and Technology - AQUA, Vol. 59, No. 1, pp. 66-78, (2010).

[6] Batterton, S., "Water Hammer: An analysis of plumbing systems, intrusion, and pump operation", Thesis submitted to the Faculty of the Virginia Polytechnic Institute and State University in partial fulfillment of the requirements for the degree of Master of Science in Civil Eng., pp. 147, (2006).

[7] Chaudhry, H. M. and Yevjevich, V., "Closed-Conduit Flow", water resources publications, P.O. Box 2841, Littleton, Colorado 80161, U.S.A., pp. 416, (1981).

[8] Choon, T., W., Aik, L., K., Aik, L., E., and Hin, T., T., "Investigation of Water Hammer Effect Through Pipeline System", International J. on Advanced Science Eng. Information Technology, ISSN: 2088-5334, Vol. 2, No. 3, pp. 48-53, (2012).

[9] Fitzgerald, R. and Van Blaricum, V. L., "Water Hammer and Mass Oscillation (WHAMO) 3.0 user's manual", (1998).

[10]Fouzi, A. and Ali, F., "Comparative study of the phenomenon of propagation of elastic waves in conduits", Proceed. of The World Congress on Eng., July 6-8, Vol. III, London, U.K, (2001).

[11] Giustolisi, O., Kapelan, Z., and Savic, D., "Extended period simulation analysis consideration valve shutdowns", J. Water Resour. Plng. And Mgmt., Vol. 134, No. 6, pp. 527-537, (2008).

[12] Jones, G. M. and Bosserman, B. E., "Pumping Station Design", Elsevier, ISBN: 978-07506-7544-4, Third Edition, (2006).

[13]Kim, S. H., "Impulse Response Method for Pipeline Systems Equipped with Water Hammer Protection Devices", Jour. of Hyd. Eng., Vol. 134, No. 7, pp. 961-969, (2008).

[14] Kirmeyer, G. J. and Lechevallier, M., "Pathogen Intrusion into Distribution Systems" AWWA Research Foundation and American Water Works Association, Denver CO, (2001).

[15] Kwon, H. J., "Computer simulations of transient flow in a real city water distribution system", KSCE, Jour. Of Civil Eng., Vol. 11, No. 1, pp. 43-49, (2007).

[16] Mohamed, H. I., "Parametric Study for the Water Hammer Phenomenon in Pipelines", $1^{\text {st } I n t . ~ C o n f . ~ o f ~ c i v i l ~ E n g . ~ S c i e n c e, ~ I C C E S 1, ~ A s s i u t, ~ E g y p t, ~ 7-8 ~ O c t ., ~ V o l . ~ I I, ~ p p . ~ 1-12, ~(2003) . ~}$

Journal of Engineering Sciences, Assiut University, Faculty of Engineering, Vol. 41, No. 6, November, 2013,E-mail address: jes@aun.edu.eg 
Moustafa S. Darweesh et al., Studying of water hammer in water supply pipes network with different abnormal operation conditions (case study-Assiut city network), pp. 2036 - 2054

[17] Nixon, W., Ghidaoui, M. S., and Kolyshkin, A. A., "Range of Validity of the Transient Damping Leakage Detection Method", Journal of Hydraulic Engineering, ASCE, September, Vol. 132, No. 9, pp. 944-957, (2006).

[18] Parmakian, J., "Water Hammer Analysis”, Dover Publications, New York, (1963).

[19]Ramos, H., Covas, D., Borga, A. and Loureiro, A., "Surge Damping Analysis in Pipe Systems: Modeling and Experiments", Vol. 42, No. 4, pp. 413-425, (2004).

[20] Richard C. and Svindland, P. E., "Predicting the Location and Duration of Transient Induced Low or Negative Pressures within a Large Water Distribution System", Master's thesis, Lexington, Kentucky, (2005).

[21] Samani, H. M. V. and Khayatzadeh, A., "Transient Flow in Pipe Networks", Jour. of Hydr. Research, Vol. 40, No. 5, pp. 637-644, (2002).

[22] Simpson, A. R. and Wu, Z. Y., "Computer Modelling of Hydraulic Transient in Pipe Networks and Associated Design Criteria", MODSIM97, International Congress on Modelling and Simulation, Modelling and Simulation Society of Australia, Hobart, Tasmania, Australia, (1997).

Journal of Engineering Sciences, Assiut University, Faculty of Engineering, Vol. 41, No. 6, November, 2013, E-mail address: jes@aun.edu.eg 
Moustafa S. Darweesh et al., Studying of water hammer in water supply pipes network with different abnormal operation conditions (case study-Assiut city network), pp. 2036 - 2054

"دراسة المطرقة المائية خلال شبكات توزيع المياة تحت ظروف تشغيل غير عادية

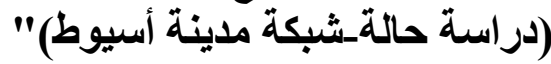

الملخص العربى

الطرق المائي هي ظاهرة غير مر غوبة تحدث في شبكات نقل وتوزيع المياه بكل أنو اعها وكل مقاساتها. وهي

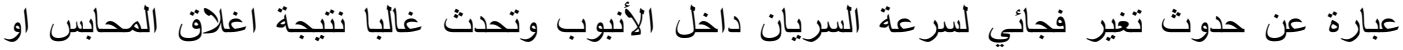

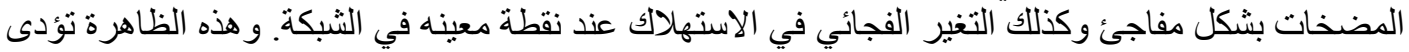

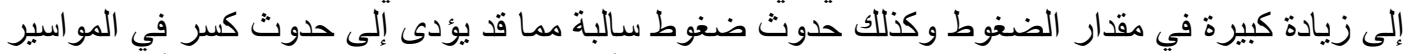

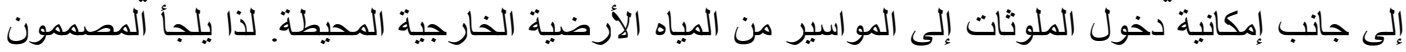

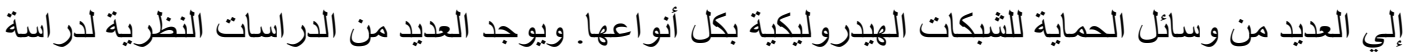

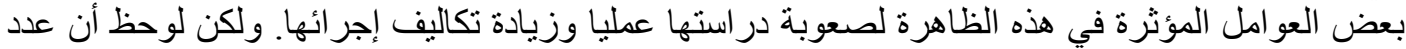

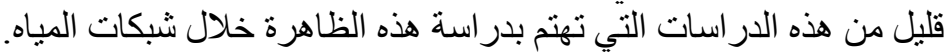

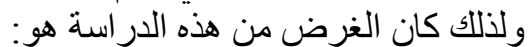

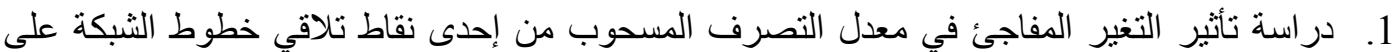

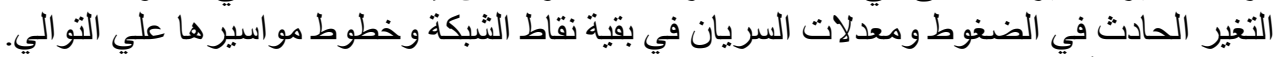

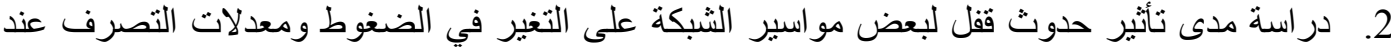

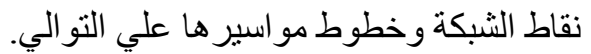

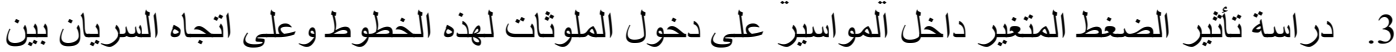

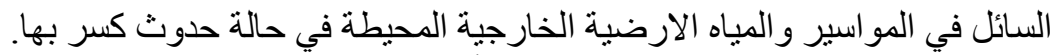

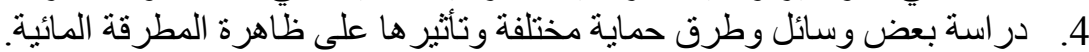
يقدم هذا البحث در اسة نظرية بإستخدام برنامج WHAMO لتحليل ودراسة الظروف الترف الغير عادية لتشغيل

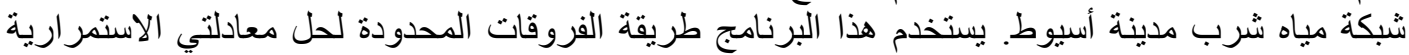

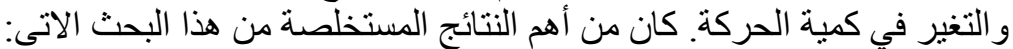

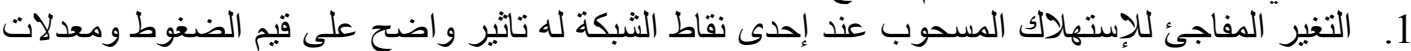

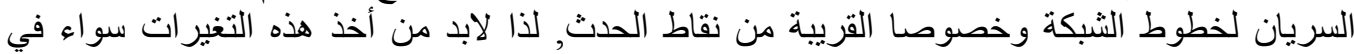

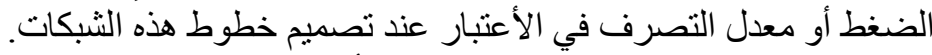

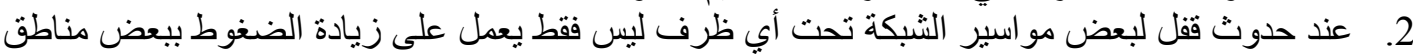

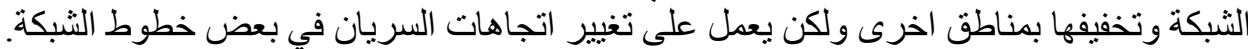

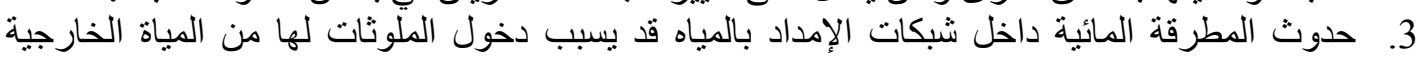

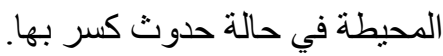

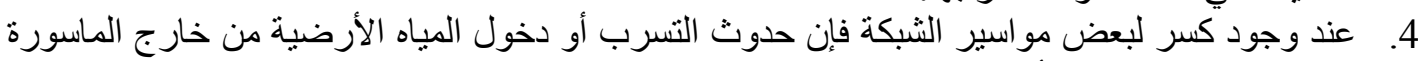

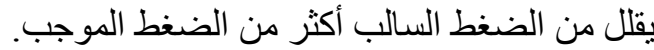

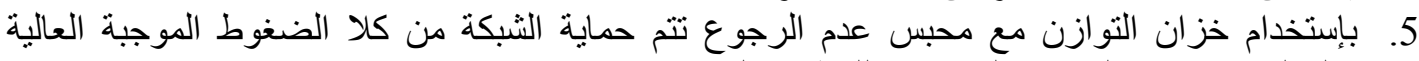

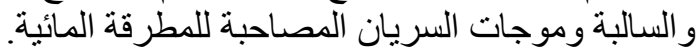

